\title{
In Situ Deformation of Thin Films on Substrates
}

\author{
MARC LEGROS,${ }^{*}$ MARTIANE CABIÉ, ${ }^{2}$ AND DANIEL S. GIANOLA ${ }^{3}$ \\ ${ }^{1}$ CEMES-CNRS, 29 rue Jeanne Marvig, 31055 Toulouse, France \\ ${ }^{2}$ CRMCN, Campus de Luminy case 913, 13288 Marseille, France \\ ${ }^{3}$ Forschungszentrum Karlsruhe, Institute for Materials Research II, Postfach 3640, 76021 Karlsruhe, Germany
}

\begin{abstract}
KEYWORDS metallic layer; interfaces; dislocations; grain boundaries; image forces; nucleation; absorption
\end{abstract}

\begin{abstract}
Metallic thin-film plasticity has been widely studied by using the difference between the coefficients of thermal expansion of the film and the underlying substrate to induce stress. This approach is commonly known as the wafer curvature technique, based on the Stoney equation, which has shown that thinner films have higher yield stresses. The linear increase of the film strength as a function of the reciprocal film thickness, down to a couple hundred nanometers, has been rationalized in terms of threading and interfacial dislocations. Polycrystalline films also show this kind of dependence when the grain size is larger than or comparable to the film thickness. In situ TEM performed on plan-view or cross-section specimens faithfully reproduces the stress state and the small strain levels seen by the metallic film during wafer curvature experiments and simultaneously follows the change in its microstructure. Although plan-view experiments are restricted to thinner films, cross-sectional samples where the film is reduced to a strip (or nanowire) on its substrate are a more versatile configuration. In situ thermal cycling experiments revealed that the dislocation/interface interaction could be either attractive or repulsive depending on the interfacial structure. Incoherent interfaces clearly act as dislocation sinks, resulting in a dislocation density drop during thermal cycles. In dislocation-depleted films (initially thin or annealed), grain boundaries can compensate for the absence of dislocations by either shearing the film similarly to threading dislocations or through fast diffusion processes. Conversely, dislocations are confined inside the film by image forces in the cases of epitaxial interfaces on hard substrates. To increase the amount of strain seen by a film, and to decouple the effects of stress and temperature, compliant substrates can also be used as support for the metallic film. The composite can be stretched at a given temperature using heating/cooling straining holders. Other in situ TEM methods that served to reveal scaling effects are also reviewed. Finally, an alternate method, based on a novel bending holder that can stretch metallic films on rigid substrates, is presented. Microsc. Res. Tech. 00:000-000, 2009. @ 2009 Wiley-Liss, Inc.
\end{abstract}

\section{INTRODUCTION}

Reliability issues have been one major concern during the fast development of microelectronics. A common source of failure arises from plastic deformation and thermal fatigue of metal interconnects. Indeed, the metallization is the softer material in an environment of semiconductors or insulators that have a much smaller coefficient of thermal expansion (CTE). As a result, thermal excursions such as those encountered by a microprocessor during its processing and later during operation can produce considerable stresses (Ames and d'Heurle, 1970). Internal stresses can add up to these thermal strains and cause plastic deformation of the metal layer (Abermann and Koch, 1985; Kubovy and Janda, 1977).

A common way to investigate thermal stresses in metallic films deposited onto rigid substrates is to measure the curvature imposed by the film to the substrate by laser profilometry. In the case of films that are much thinner than the substrate, the Stoney's equation (Stoney, 1909) reduces to the simple equation:

$$
\sigma_{\mathrm{f}}=\frac{E_{\mathrm{s}} t_{\mathrm{s}}^{2}}{6\left(1-v_{\mathrm{s}}\right) t_{\mathrm{f}}}\left(\frac{1}{R}-\frac{1}{R_{0}}\right)
$$

where $\sigma_{\mathrm{f}}$ is the average biaxial stress in the film with thickness $t_{\mathrm{f}}, E_{\mathrm{s}}, v_{\mathrm{s}}$, and $t_{\mathrm{s}}$ are, respectively, the Young's modulus, Poisson's ratio, and thickness of the substrate. $R_{0}$ is the radius of curvature of the substrate before the film is deposited, whereas $R$ is the substrate curvature measured after deposition and/or during the heating experiments.

The robustness of this equation and measurement method lies in the fact that $\sigma_{\mathrm{f}}$ is calculated from the measurement of $R$ without any assumption about the film elastic properties, as only those of the substrate

*Correspondence to: M. Legros, CEMES-CNRS, 29 rue Jeanne Marvig, BP 94347, 31055 Toulouse Cedex 4, France. E-mail: legros@cemes.fr

Received 31 March 2008; accepted in revised form 1 October 2008

Contract grant sponsors: Stressnet and ESTEEM networks and the ANR

P-Nano Project Cristal.

DOI 10.1002/jemt.20680

Published online in Wiley InterScience (www.interscience.wiley.com). 


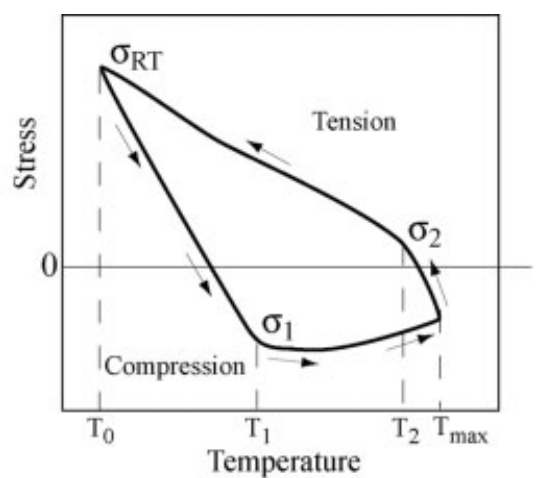

(a)

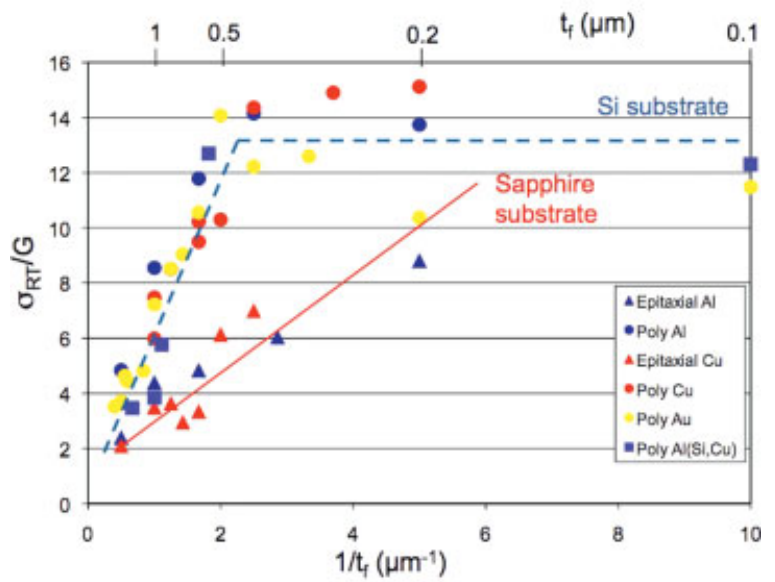

(b)

Fig. 1. (a) Typical stress-temperature cycle for a 1- $\mu$ m-thick polycrystalline $\mathrm{Al}$ film on oxidized $\mathrm{Si}$ substrate $\left(T_{\max } \approx 450^{\circ} \mathrm{C}\right)$. (b) Compilation of the room temperature strength $\left(\sigma_{\mathrm{RT}}\right)$ normalized by the shear modulus $(G)$ for various thin films with an epitaxial interface (sapphire substrate) or incoherent interface (Si substrate) as a function of film thickness. Data extracted from (Bostrom, 2001; Dehm et al., 2003; Leung, 2001; Müllner and Arzt, 1998).

are needed (Flinn et al., 1987). For metallic films deposited onto Si or ceramic-type substrate, the stress is imposed on the film by varying the temperature of the sample, typically between 20 and $400-600^{\circ} \mathrm{C}$. The difference in CTE between the two materials is generally sufficient to strain the film first elastically, and then plastically, even if the amount of strain remains small (see the end of this paragraph). A typical thermal cycle where the film yields first in compression (during heating) before being stressed in tension upon cooling is shown in Figure 1a. From this type of stress/temperature cycle, one can measure two yield stresses $\left(\sigma_{1}\right.$ in compression and $\sigma_{2}$ in tension) and the stress at the end of the cycle, noted $\sigma_{\mathrm{RT}}$ because it usually corresponds to room temperature. It has been shown that $\sigma_{1}, \sigma_{2}$, or $\sigma_{\mathrm{RT}}$ increase as the inverse of the film thickness $t_{\mathrm{f}}$ for thicker films and then plateaus in the case of thinner films. The transition between the strengthening and plateau region (400 $\mathrm{nm}$ in Fig. 1b) is still under debate, but seems to occur at around $200 \mathrm{~nm}$ when thermal cycles are run down to $-100^{\circ} \mathrm{C}$ (Eiper et al., 2007). A purely technical reason for the leveling of the yield stress in thinner films could be that the amount of plastic strain reaches zero for 200-nm-thick films tested to $500^{\circ} \mathrm{C}$. For this temperature amplitude, thinner films are thus elastically stretched and do not reach their yield stress.

The strengthening of thinner films has been rationalized in term of threading dislocations, whose motion is confined in the metal layer because of image forces generated by a stiff substrate (Freund, 1987; Nix, 1989). According to these models, the plastic yielding of the layer corresponds to the motion of the first threading dislocations, and trailing in their wake is a segment of interfacial dislocation. This motion is possible when the increase in interfacial dislocation energy due to the length increase and the work of image forces equals the film strain energy reduction. Balancing these two terms leads to the Nix-Freund relation, establishing that the yield stress varies as $1 / t_{f}$. If this basis is correct, then absolute values of the strength would be much lower than experimental measurements for films that have an amorphous interface with the substrate. This approach has been refined to take into account grain orientations and boundaries in polycrystalline films (Arzt, 1998; Chaudari, 1979; Thompson, 1993), and even hardening because of interfacial dislocations (Nix, 1989), but the calculated stresses always fell short compared with actual experimental stress values of polycrystalline films on oxidized $\mathrm{Si}$ substrates (Dehm et al., 2001a). Surprisingly, the stress levels of epitaxially grown $\mathrm{Al}$ and $\mathrm{Cu}$ films on sapphire substrates (Dehm et al., 2003) are in good agreement with the threading dislocation theory (Fig. 1b), even if these films are polycrystalline. According to the Nix-Freund theory, the effect of a stiffer substrate should increase the confinement of dislocations in the metallic film and thus lead to higher yield stresses (Ovecoglu et al., 1987). Experimentally, the reverse is observed. This discrepancy underlines the fact that the current plastic relaxation mechanisms in metal films are insufficiently known to be implemented in simulations or computational models requiring mechanistic input (Nicola et al., 2005): such calculations reproduce the $1 / t_{\mathrm{f}}$ slope of the stress increase, but like the Nix-Freund equation, underestimates its value (Weihnacht and Bruckner, 2001). Attempts to model the complete stress/temperature cycles using discrete dislocation calculations proved also difficult, and the approach of using the Frost and Ashby deformation mechanisms maps established for bulk materials (Frost and Ashby, 1982) has been abandoned because it fails to reproduce recent and clean experimental thermal cycles (Thouless, 1995).

The plateau region, where the strengths of the thinner films do not increase any more with decreasing thickness (Fig. 1b), is even less understood, and there are no plasticity theories available to fully explain it. An alternative to dislocation-based plasticity has however been imagined by Gao et al. (1999). In this model, which is applicable to ultrathin polycrystalline metal films with no adhesive native oxide (e.g., $\mathrm{Cu}, \mathrm{Au}$ ), the stress relaxation occurs in compressed films by the transport of excess matter to the surface via the grain boundaries. A complete stress relaxation of the layer is 
possible through this mechanism, similar to Coble creep. One of the first experimental supports of this theory was the observation by Balk et al. of parallel dislocation glide in ultrathin $\mathrm{Cu}$ films strained using in situ TEM (Balk et al., 2003).

The theme of confined plasticity is not restricted to thin films; recent micropillars and microtensile experiments succeeded at producing stress-strain curves for micron, submicron-sized specimens (Greer et al., 2005; Kiener et al., 2008), and nanocrystalline metals (Gianola et al., 2006; Legros et al., 2008a,b) where dislocation-free paths are limited. Whether the volume is limited by interfaces or free surfaces, a size-dependent evolution of the yield stress is observed in these tiny structures, and theories based on the balance between dislocation nucleation and dislocation absorption at the free surfaces have emerged. The so-called "dislocation starvation" hypothesis states, for example, that the first dislocations present in these very small volumes escape very rapidly from the crystal via the free surfaces, leaving a dislocation-free structure where nucleation of additional dislocations dictates the stress evolution (see the work from Minor et al. in this issue). Molecular dynamics simulations (Van Swygenhoven et al., 2006) and prior in situ TEM work (Müllner and Arzt, 1998) have proved that a similar dislocation absorption could happen at grain boundaries or at heterogeneous interfaces. The restrained motion of dislocations in small scale structures implies a change in their mechanical properties: an increased yield stress and lower ductility are indeed experimentally observed. This change in mechanical response was anticipated on the basis of the Hall-Petch relationship for nanocrystals and the Mathews-Blakeslee (Matthews and Blakeslee, 1974, 1975) or Nix-Freund (Freund and Jonsdottir, 1993; Nix, 1989) models for films on substrate. In both cases, the increased yield stress stems from the blocking actions of grain boundaries or interfaces on dislocations. These simple models have however shown their limitation in explaining how nanometer-sized structures deform plastically.

In situ TEM proved to be very effective at directly observing the microstructural changes induced by thermal cycling of thin films. We will see in this work that both cross-sectional (Inkson et al., 2002; Legros et al., 2000a, 2002, 2003) or plan-view (Dehm et al., 2001a,b; Kobrinsky and Thompson, 2000) approaches can be adopted and lead to complementary information regarding the plastic mechanisms operating in thin metallic films. We will also see that in situ TEM provides a direct way to confront existing models, especially those based on easily observable defects such as dislocations by dynamically displaying the fine mechanisms of plastic deformation as they operate.

\section{MATERIALS AND METHODS Processing of Metallic Films}

Pure Al Films. Bare and passivated pure Al films were sputter-deposited on $620-\mu \mathrm{m}$-thick and 10 -cm-diameter (100) oxidized Si wafers at $100^{\circ} \mathrm{C}$ at the Lincoln Laboratory (Cambridge, MA). Al films studied here were 630 or $1,000 \mathrm{~nm}$ thick. The amorphous oxidation layer $(18.5 \mathrm{~nm})$ on the wafer served as a diffusion barrier between the deposited $\mathrm{Al}$ and the Si substrate. A much thicker $\mathrm{SiO}_{\mathrm{x}}$ passivation layer (500 or $1,000 \mathrm{~nm}$ ) was deposited on half of the specimens by low-pressure chemical vapor deposition (LPCVD) at a temperature of $300^{\circ} \mathrm{C}$. This very thick passivation layer imposes that the stress measured during wafer curvature experiments remains compressive in the $\mathrm{Al}+\mathrm{SiOx}$ dual film (Legros et al., 2002), but that the Al film still goes from tension to compression with varying temperature. Note that in this previous work (Legros et al., 2002), the component of the stress due to SiOx has not been subtracted in the stress versus temperature curves. $\mathrm{Al}$ films deposited as single crystals on $\mathrm{NaCl}$ substrates were subsequently spin-coated with $\sim 10-\mu \mathrm{m}$-thick polyimide at Max Planck Institute (MPI—Stuttgart, Germany). A stretchable structure made of $\mathrm{Al}$ film on polyimide was then obtained by dissolving the salt substrate (Dehm et al., 2006).

Al(Si,Cu) Films. Al (550 nm; 1 wt \% Si, 0.5 wt \% $\mathrm{Cu})$ films were deposited at $450^{\circ} \mathrm{C}$ onto oxidized $6^{\prime \prime}$ (100) Si wafers by magnetron sputtering at ST Microelectronics (Rousset, France). Initially $680-\mu \mathrm{m}$-thick wafers were mechanically and chemically back polished to a final $180 \mu \mathrm{m}$ thickness.

Au Films. Preparation of Au films was done at Stanford University (Stanford, CA). Prior to deposition of Au films, 200- to 500- $\mu \mathrm{m}$-thick and 10-cm-diameter (100) Si wafers were first coated on both sides at room temperature with 150-nm LPCVD silicon nitride which acts as a diffusion barrier between the silicon and the gold film. A 10-nm titanium or tungsten adhesive layer was then deposited onto the silicon nitride using electron-beam evaporation. Finally, e-beam evaporation served to lay down gold films with thicknesses ranging from 100 to 2,500 nm onto the titanium or tungsten adhesion layer at room temperature. Some of the films were subsequently passivated with $\mathrm{Si}_{3} \mathrm{~N}_{4}$ using plasma-enhanced CVD at $350^{\circ} \mathrm{C}$.

Cu Films. Epitaxial Cu films (1,000 nm) on sapphire were prepared at MPI-Stuttgart, using ultra high vacuum molecular beam epitaxy. Cu was deposited at room temperature on previously cleaned (0001) $\alpha$ $\mathrm{Al}_{2} \mathrm{O}_{3}$ substrates at a rate of $0.5 \mathrm{~nm} / \mathrm{min}$. The epitaxial relationship between $\mathrm{Cu}$ and sapphire was $(111) \mathrm{Cu} / /$ $(0001) \mathrm{Al}_{2} \mathrm{O}_{3}$ and $<\overline{1} 10>\mathrm{Cu} / /<\overline{1} 010>\mathrm{Al}_{2} \mathrm{O}_{3}$.

We will not discuss in this article the role of bonding layers such as $\mathrm{Ti}, \mathrm{Ta}$, etc. that are added between the substrate and the metallic film to promote the adhesion of the film (Schmidt et al., 2004). Adhesion layers are usually a few $\mathrm{nm}$ thick, polycrystalline and do not participate in the plastic relaxation of the main layer.

\section{In Situ TEM Sample Preparation}

Plan-View Samples. This type of sample preparation is relevant here only for metallic films that are thin enough to be electron transparent, even with a portion of the substrate remaining in the thinnest zone. Two types of plan-view TEM samples were prepared for in situ thermal cycling and straining.

Films on hard substrates (Si) were dimpled and ionetched according to Figure 2. The difficulty was to stop the etching before reaching the film so that a thin layer of substrate remains under the film but does not block the electron beam. Removal of all the substrate prevents the transmission of stress to the film during thermal cycling and no microstructure changes are to be expected (Gerth et al., 1994). Theoretically, the full 

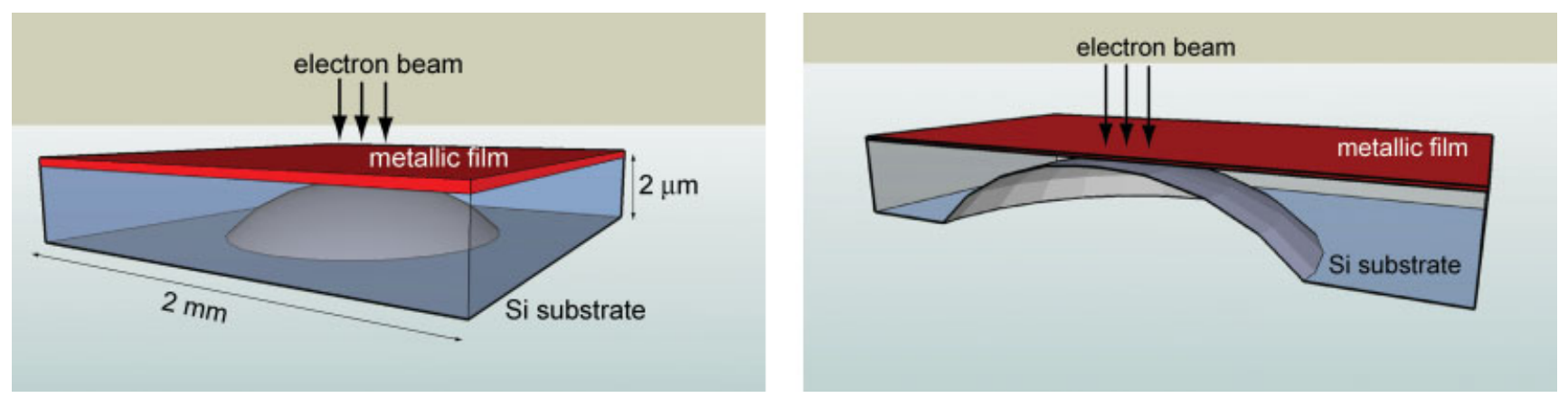

Fig. 2. Plan-view specimen for in situ TEM heating experiments. Observation of the metallic film (red) deposited on rigid substrate (blue) is only possible for the thinnest films ( $\leq 300 \mathrm{~nm}$ for $\mathrm{Al}$ at 200 $\mathrm{kV}$ ). The dimple made in the substrate window does not reach the metallic film. [Color figure can be viewed in the online issue, which is available at www.interscience.wiley.com.]
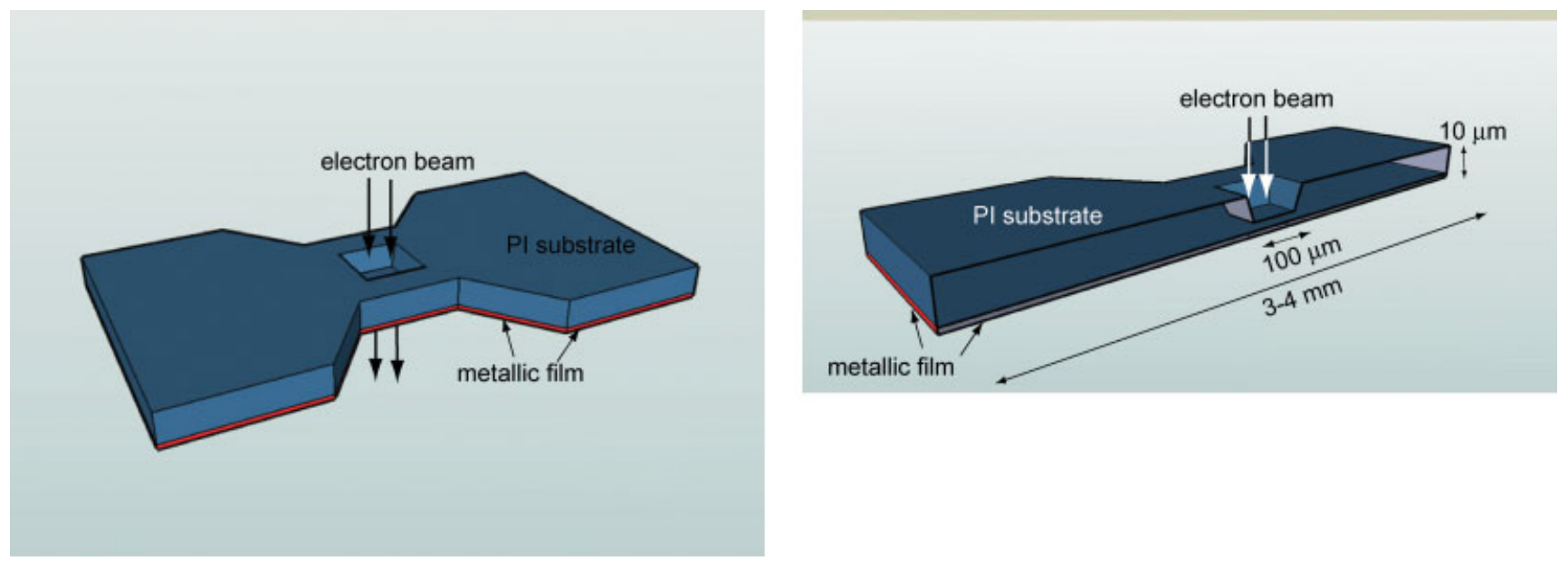

Fig. 3. Sketch of a stretchable plan-view specimen for in situ TEM observation of an $\mathrm{Al}$ film (red) deposited on polyimide substrate (blue). The square window is carved in the polyimide using a focused Gallium ion beam. [Color figure can be viewed in the online issue, which is available at www.interscience. wiley.com.]

substrate thickness can be retained outside the dimpled zone. Practically, dimplers make cavities that are too shallow for implementation on substrates that are thicker than 50-80 $\mu \mathrm{m}$. For typical $2 \times 2 \mathrm{~mm}^{2}$ or $\emptyset$ 3 -mm circular TEM samples, the Si substrate was thus polished down to $\sim 30 \mu \mathrm{m}$. After dimpling and ion milling, the goal was to leave $\sim 100 \mathrm{~nm}$ or less of the Si substrate under the film.

Stretchable specimens (Fig. 3) were carved from metal on polyimide foils using a focused ion beam (FIB). First, the edges were cut to give the sample a dog bone-like shape and concentrate the stress in the center region. A $100 \times 100 \mu^{2}$ window was then etched with Ga ions (FIB) from the polyimide side. The polyimide left under the film was about $1-2 \mu \mathrm{m}$ thick. This type of sample, first described by Dehm et al. (2006), was then glued with epoxy or cyanocrylate on stretchable copper grids fitting in straining holders.

Cross-Sectional Samples. For thicker films or when the interaction between the dislocations and the interface is of prime importance, a cross-sectional configuration offers a good alternative to plan-view samples. Although optional, gluing two pieces of substrate and film together using a hard epoxy (marked "glue" in Fig. 4) helps preventing polishing damage on the metallic film, especially when the specimens are not passivated. Tripod polishing results in wedge-shaped samples in which the thinner part is electron transparent (Fig. 4). To make an in situ TEM sample, the goal is to place the film/substrate interface in the thinnest part of the wedge. Only one side is fully supported by the initial substrate thickness. The thinner part of the wedge contains one or two thin strips of the initial film, thus considered as a "nanowire" on a substrate. Depending on the materials involved, the width of this strip (along the electron beam path) can be about $100-300 \mathrm{~nm}$, whereas its height corresponds to the initial film thickness. The Si part of the wedge is then glued with high-temperature epoxy or cement on a $\mathrm{Cu}$ grid and can subsequently be heated using a heating holder.

Figure 5 illustrates the predicted stress levels because of the difference in CTE in the full specimens (thin film on a cm-sized Si wafer, Fig. 5a) and in a cross-sectional wedge of the same material (Fig. 5b) for the same temperature increase. The Von Mises stresses 


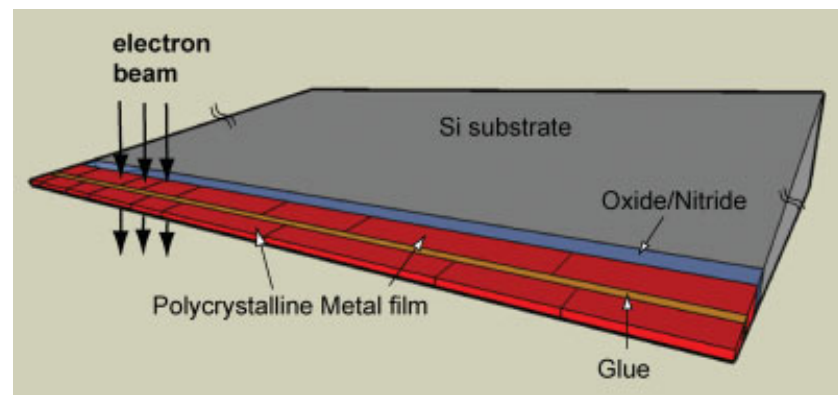

Fig. 4. Sketch of a typical wedge-shaped cross-sectional specimen for in situ TEM observation of a polycrystalline metal film (red) deposited on a $\mathrm{Si}$ substrate coated with an amorphous oxide or nitride layer.

are shown and do not fully reproduce the stress tensor in the wedge sample. The stress level is $20 \%$ smaller in the wedge when compared with the full specimen. Compared with the bidimensional compression state of the film on the full substrate, the "nanowire" is stressed primarily along one dimension corresponding to its length. Still, the difference in absolute values of stress is small along the thin wedge and one can expect similar activation of plastic mechanisms in both the full specimen and the wire upon thermal cycling. The wedge shape of the specimen also helps to avoid buckling effects when the film goes successively between tension and compression. An experimental validation of this technique can be found in Legros et al. (2002), where two wires in a configuration similar to Figure 4 , undergo thermal cycling. Microstructural changes only occur in the stressed specimen (attached to the substrate). The very fine stress control obtained with this technique has recently been employed to control the dislocation motion between $\mathrm{Si}$ precipitates in an alloyed $\mathrm{Al}$ film, leading to the quantification of the pipe-diffusion mechanism (Legros et al., 2005b, 2008a).

Electron transparency at the tip of the wedge is usually obtained with tripod polishing using fine diamond polishing papers and colloidal silica. However, certain materials such as Au films that need to be thinner than $150 \mathrm{~nm}$ and $\mathrm{Cu}$ films on sapphire substrates that cannot be polished with silica require additional thinning. This final thinning step is performed using ion milling, and in this study, a Gatan PIPS operating at $5 \mathrm{keV}$ was employed. A Zeiss/Orsay Physics cross-beam XB 1540 FIB was used to prepare the bending sample presented at the end of this work (Fig. 14).

In situ TEM observations reported in this work were conducted with a JEOL 2010 microscope operating at $200 \mathrm{kV}$. The TEM is equipped with a MegaView III CCD camera from Soft Imaging System. Dynamic images are recorded on a DVD/hard drive video recorder, whereas still pictures are digitized on a PC. Both can be subsequently edited using common video and image editing software. A room-temperature straining holder was utilized to deform the metal films deposited on polymers, whereas a high-temperature double tilt holder served to achieve the temperature cycles necessary to plastically deform the metal films deposited on hard substrates ( $\mathrm{Si}$, sapphire). Thermal cycles up to 450 and $500^{\circ} \mathrm{C}$ were performed for $\mathrm{Al}$ and

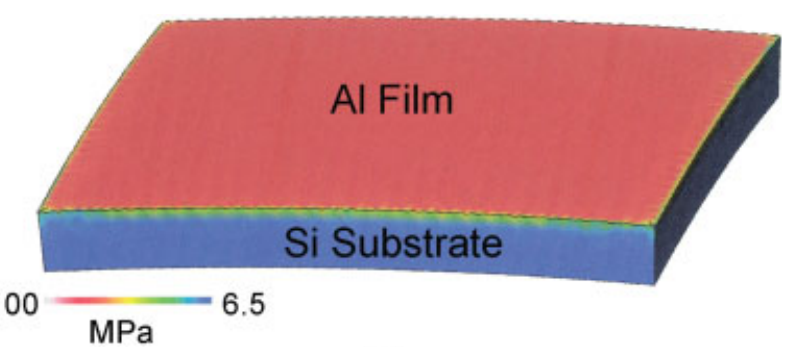

(a)

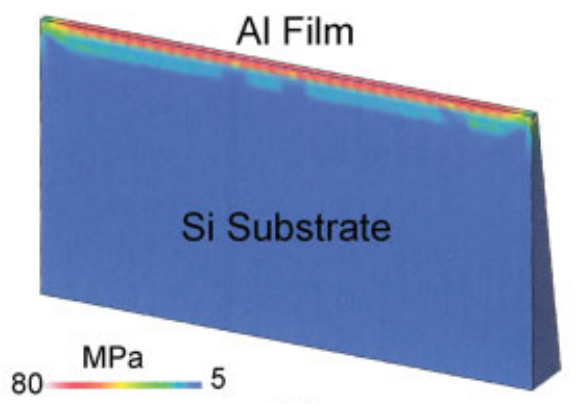

(b)

Fig. 5. Finite element simulation showing the Von Mises stresses generated by a temperature change of $50^{\circ} \mathrm{C}$ in (a) a full specimen $(1 \mathrm{~cm} \times 2 \mathrm{~cm} \times 0.5 \mathrm{~mm}$, typical size used in wafer curvature $)$ and (b) in a wedge cross-section. The difference in CTE between the 1- $\mu \mathrm{m}-$ thick Al film and the 500- $\mu$ m-thick Si substrate strain the film in compression given an increase in temperature. The wedge has dimensions of $2 \mathrm{~mm} \times 0.5 \mathrm{~mm}$ and $0.3 \mu \mathrm{m}$ at the top. SolidWorks ${ }^{\mathbb{R}}$ software calculations courtesy of J. P. Feiereisen.

$\mathrm{Cu}$ films, respectively. The heating rate was typically $20^{\circ} \mathrm{C} / \mathrm{min}$, higher than that commonly employed in wafer curvature experiments (closer to $5^{\circ} \mathrm{C} / \mathrm{min}$ ).

\section{RESULTS \\ In Situ Thermal Cycling: General Observations}

Plan-view observations were made only on $\mathrm{Al}, \mathrm{Al}(\mathrm{Si}$, $\mathrm{Cu}$ ), and $\mathrm{Au}$ films on oxidized Si because no sufficiently thin $\mathrm{Cu}$ films on sapphire were available. For $\mathrm{Al}$ and $\mathrm{Al}(\mathrm{Si}, \mathrm{Cu})$ films, our observations show that ultrathin films (less than $200 \mathrm{~nm}$ ) have a very low initial dislocation density. In situ thermal cycling to $450^{\circ} \mathrm{C}$ causes very limited dislocation activity, resulting in the conservation or slight decrease of the dislocation density. During the in situ experiments, traces of interfacial dislocations left by threading segments were either absent or rapidly disappeared above $250^{\circ} \mathrm{C}$. Scarce grain boundary movements were observed, but this point will be developed later. Cracking of 100-nm Au thin films was systematically observed prior to any dislocation movements either during the heating or cooling ramp of the first cycle. The crack originated from the thinnest dimpled region and was followed by a heavy curling of the specimen, denoting a strong stress increase.

Thermal cycling of cross-sectional samples of metal film on ceramic-type substrate always resulted in a more substantial decrease in dislocation density, especially for thicker films (500-1,000 nm) where the initial 


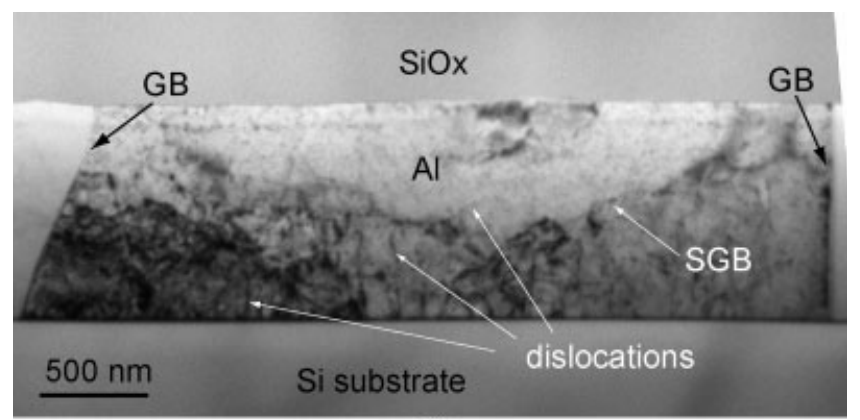

a)

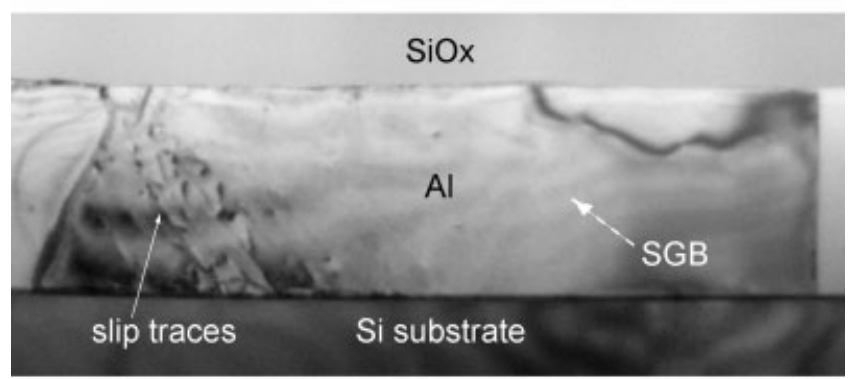

b)

Fig. 6. Evolution of the dislocation structure in a cross-sectional sample of a passivated 1- $\mu \mathrm{m} \mathrm{Al} \mathrm{film} \mathrm{deposited} \mathrm{on} \mathrm{an} \mathrm{oxidized} \mathrm{sub-}$ strate. $\mathbf{a}$ and $\mathbf{b}$ represent the same grain after a thermal cycle between 20 and $450^{\circ} \mathrm{C}$ inside a TEM. GB indicates grain boundaries and a subgrain boundary (SGB) that has disappeared during the in situ experiment.

density was higher than in very thin films (200 $\mathrm{nm}$ and below). At least during the first cycle, plastic deformation occurred in the same temperature range than for plain films on wafers tested in wafer curvature experiments. For a $1-\mu \mathrm{m}$ Al film cycled to $400^{\circ} \mathrm{C}$, this plastic deformation typically takes place between 150 and $400^{\circ} \mathrm{C}$ during heating and from 350 down to $50^{\circ} \mathrm{C}$ in the cooling stage. Figure 6 illustrates the case of an $\mathrm{Al}$ film deposited on an oxidized Si substrate and subsequently passivated with a thick $\mathrm{SiO}_{\mathrm{x}}$ layer. As a result, the metal layer lies between two amorphous Si oxide layers, one being very thin (20 nm thermally grown on the Si substrate surface prior to Al deposition) and the second much thicker (passivation layer: $1 \mu \mathrm{m}$ ). One can see that the dislocation density drops dramatically between the initial state (Fig. 6a) and the end of a thermal cycle (Fig. 6b), from 20 to $450^{\circ} \mathrm{C}$. In Figure 6a, the contrast is blurred by the presence of these initial dislocations and the implantation defects due to ion polishing. A low angle boundary (or subgrain boundary$\mathrm{SGB}$ ) is also initially present in Figure 6a. After one thermal cycle, only a few dislocations remain on the left of the figure. Most of the dark lines are slip traces that characterize the slip of the remaining dislocations during the cooling of the sample. The grain boundaries that limit both sides of the grain are static, but the SGB, seen in Figure 6a, has disappeared in Figure 6b.

Similar experiments performed on $\mathrm{Cu}$ films on sapphire (Fig. 7) also led to analogous dislocation loss. In this study, dislocations densities have been measured more systematically in cross section. Because of irradi- ation damages, essentially at the surface of the foils, the measured initial density $10^{10}-10^{11} \mathrm{~cm}^{-2}$ can be considered as an upper limit in 0.5- to $1-\mu \mathrm{m}$ thick $\mathrm{Al}$ and $\mathrm{Cu}$ films (regardless of the interface type). The actual initial density may be closer to $10^{10} \mathrm{~cm}^{-2}$. For the same in situ cross-sectional thermal cycling experiment, the final dislocation density remained above $10^{9}$ $\mathrm{cm}^{-2}$ in the case of epitaxial $\mathrm{Cu}$ films, whereas densities of $10^{7}, 10^{8} \mathrm{~cm}^{-2}$ (as in Fig. 6b) were commonly achieved in cross-sectional Al films with a heterogeneous interface. It also requires more cycles to reach a lower density limit in $\mathrm{Cu}$ films: for instance, three cycles were needed to attain the dislocation configuration of Figure 7. For the same in situ configuration, the dislocation loss in $\mathrm{Al}$ films with a crystalline/amorphous interface is thus much more severe than in the case of $\mathrm{Cu}$ films that have a crystalline/crystalline interface with the substrate.

\section{Role of the Film/Substrate Interface on the Dislocation Density}

The first reason for the dislocation density decrease in $\mathrm{Cu}$ and $\mathrm{Al}$ films is geometric, as thin film strips (or wires) have two more free surfaces that allow dislocations to escape (Figs. 4 and 5) when compared with the full film on its substrate. The second reason addresses the behavior of the film/substrate interface. In the case of Al films that are sandwiched between two silica layers, the dislocations are absorbed at the crystalline/ amorphous (incoherent) interface as exemplified in Figure 8. This figure is made of four still frames extracted from a video sequence taken during the first thermal cycling experiment on a passivated $\mathrm{Al}$ film observed in cross-section (configuration similar to Figs. 4 and 5). In Figure 8a, a dislocation loop $d_{1}$ is pinned by another dislocation inside the crystal at one end (left) and at a grain boundary at the other end (right). When unpinned from the GB on the right, the dislocation turns around its left end and sweeps over interface 1 (Fig. 8b). As attested by the time interval and the absence of remaining contrast at this interface, no interfacial dislocation is left and the interface does not constitute an obstacle for the dislocation motion. Note the angle $\theta$ made by the dislocation with this interface (about $60^{\circ}$ ) in Figure $8 \mathrm{~b}$ and its subsequent value (closer to $90^{\circ}$ ) in Figure 8c. The second interface (interface 2, Fig. 8c) is made of a thicker $\mathrm{SiO}_{\mathrm{x}}$ layer, but dislocations behave similarly. In Figure $8 \mathrm{c}$, a dislocation loop $d_{2}$ is pinned between two obstacles inside the $\mathrm{Al}$ crystal. Upon expanding, the loop going toward interface 1 is partially stopped inside the crystal, whereas the part of the loop reaching interface 2 annihilates instantly (Fig. 8d). Only the slip traces are visible, indicating that some of the dislocation loop is temporarily blocked at the native oxide on the $\mathrm{Al}$ film side. No such contrast is visible at interface 2 at the location where $d_{2}$ has encountered the interface. Not only does this suggest that $\mathrm{Al} / \mathrm{SiO}_{\mathrm{x}}$ interfaces behave like free surfaces with respect to dislocations but also that actual free surfaces of the $\mathrm{Al}$ strip covered with native oxide are more efficient at retaining some of the strain carried by a dislocation inside the $\mathrm{Al}$ crystal.

To quantify the effect of the obstacle that represents the $\mathrm{Al} / \mathrm{SiO}_{\mathrm{x}}$ interface on the motion of threading dislocations, we have measured the angle $\theta$ between these 
Free surface

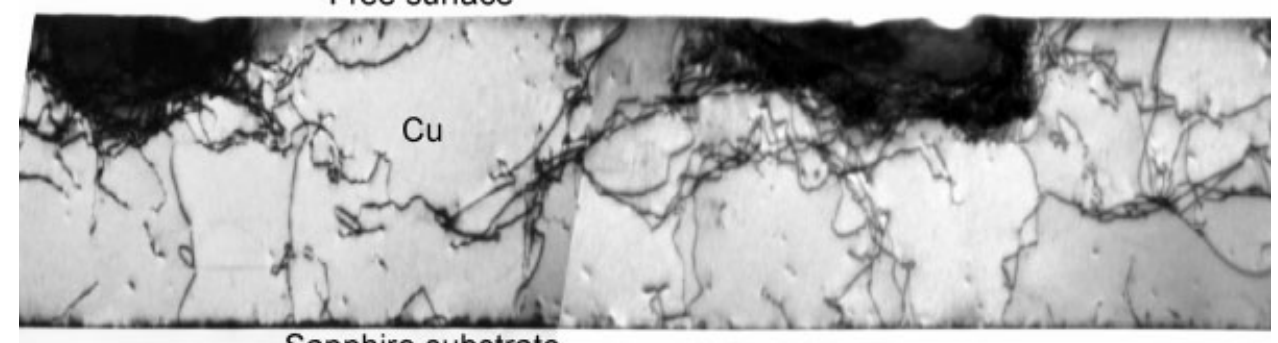

Sapphire substrate

a)

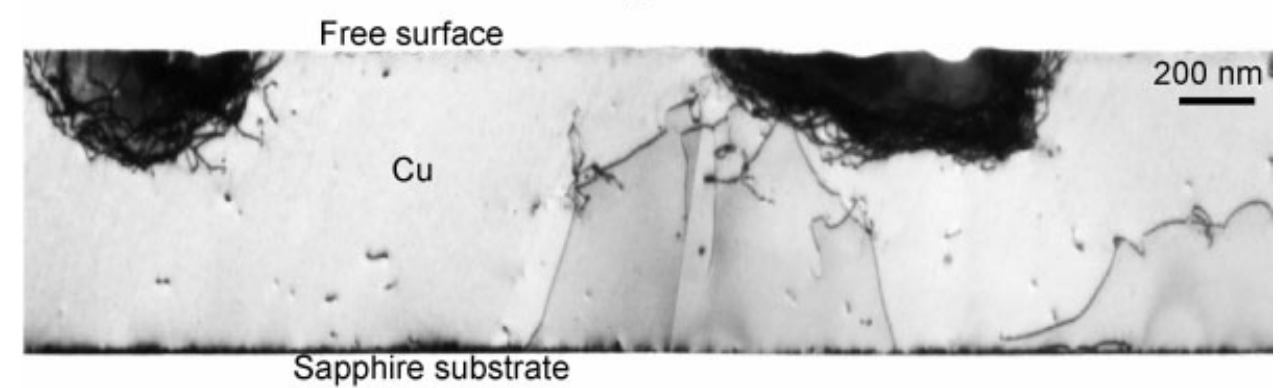

b)

Fig. 7. Evolution of the dislocation structure in a cross-sectional sample of a $\mathrm{Cu}$ film deposited on a sapphire substrate. (a) Before thermal cycling, (b) after three thermal in situ cycles between 20 and $450^{\circ} \mathrm{C}$ inside a TEM.

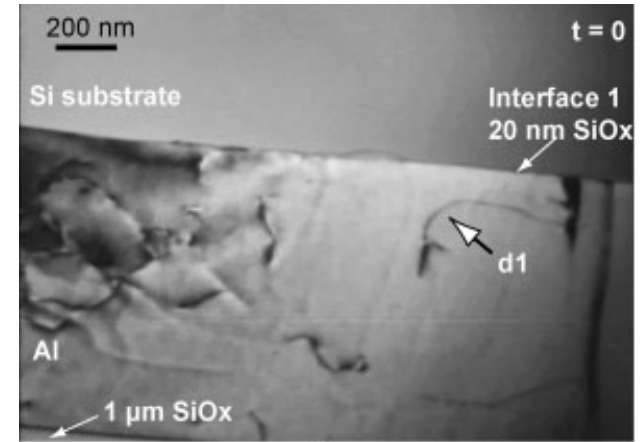

a)

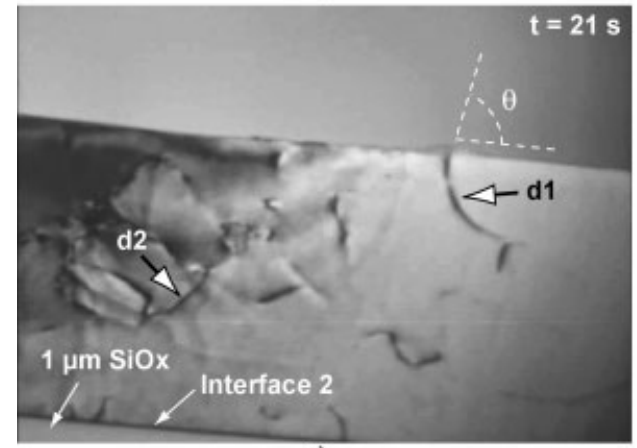

c)

Fig. 8. Absorption of dislocations by $\mathrm{Al} / \mathrm{SiO}_{\mathrm{x}}$ interfaces. In situ sequence taken between 270 and $290^{\circ} \mathrm{C}$ during the first heating. Cross-sectional view of a 1- $\mu \mathrm{m}$ Al film passivated with $1-\mu \mathrm{m} \mathrm{SiO}_{\mathrm{x}}$ and deposited on an oxidized Si substrate. Between $(\mathbf{a})$ and $(\mathbf{d})$, dislocation $d_{1}$ expands toward interface 1 similarly to a free surface. Note that

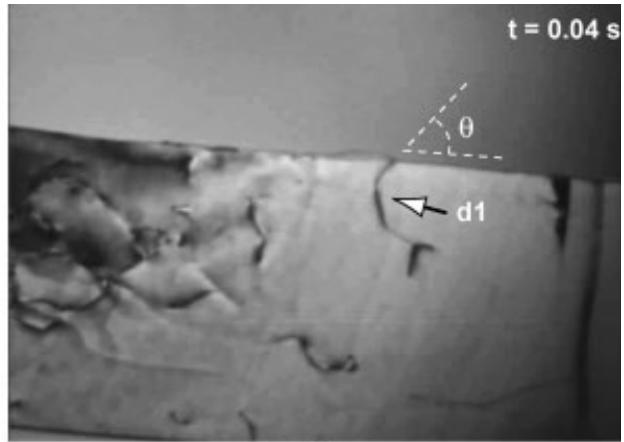

b)

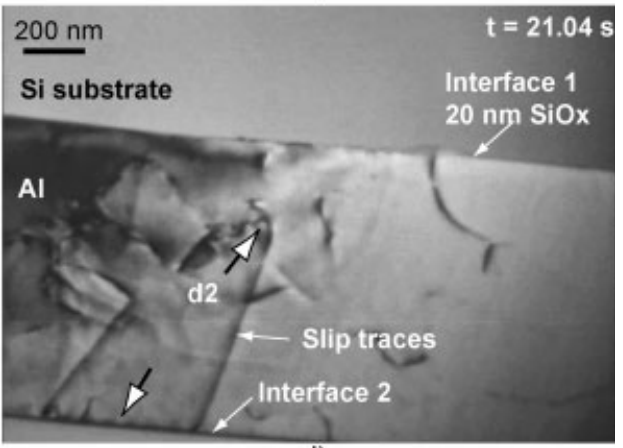

d)

the dislocation loop $d_{2}$, when expanding toward interface 1 substrate $(\mathbf{c}, \mathbf{d})$ is stopped in the middle of the Al layer by other dislocations, whereas the part expanding toward interface 2 (passivation layer) disappear within one video frame $(0.04 \mathrm{~s})$. 
dislocations and the interface at different positions of their pathway (see positions 1-4 in Fig. 9b) from the video sequence, just before they moved to their next position. This distribution of angles, established for several dislocations between 200 and $350^{\circ} \mathrm{C}$ during one heating and one cooling ramp, is represented in

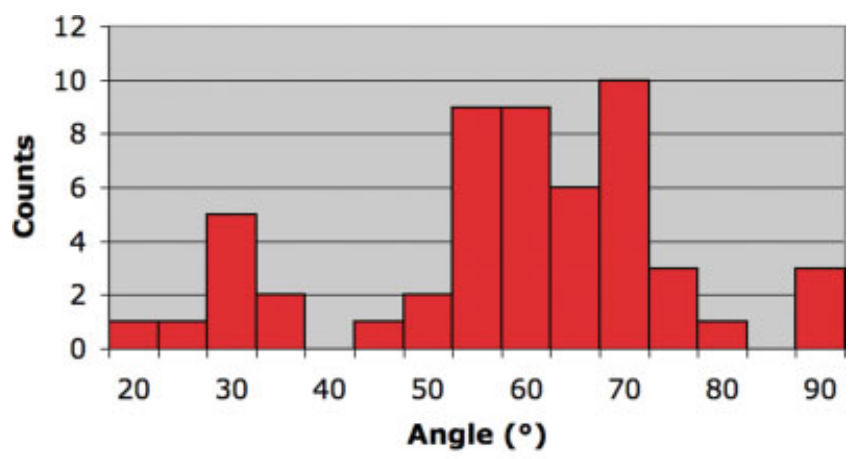

(a)

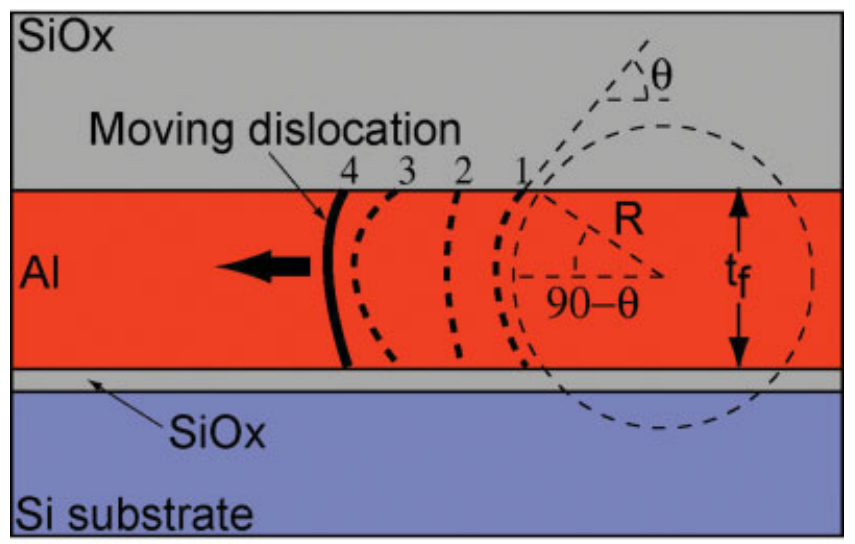

(b)

Fig. 9. Release angle of threading dislocations of passivated $\mathrm{Al}$ films at the $\mathrm{Al} / \mathrm{SiO}_{\mathrm{x}}$ interfaces. (a) Distribution of release angles $\theta$ during an in situ thermal cycling of $1 \mu \mathrm{m}$ passivated $\mathrm{Al}$ film. (b) Sketch of the relation between the radius of curvature of a moving dislocation lightly pinned at both $\mathrm{Al} / \mathrm{SiO}_{\mathrm{x}}$ interfaces and its release angle $\theta .1-4$ represent the successive position of the moving threading dislocation at the $\mathrm{Al} / \mathrm{SiO}_{\mathrm{x}}$ interface (see Fig. 8). [Color figure can be viewed in the online issue, which is available at www.interscience. wiley.com.]
Figure 9a. The average angle is close to $60^{\circ}$, representing a position similar to dislocation $d_{1}$ in Figure $8 \mathrm{~b}$. When the dislocation density has significantly dropped, threading dislocations connect one interface to the other and the release angle can therefore be linked to the radius of curvature of the dislocation, as described in Figure 9b. This figure shows that the radius of curvature $R$ is linked to the film thickness $t_{\mathrm{f}}$ and the release angle $\theta$ by the relation:

$$
R=\frac{t_{\mathrm{f}}}{2 \cos \theta}
$$

As will be discussed later, a completely "transparent" surface would lead to an angle close to $90^{\circ}$, whereas an interface perfectly resistant to dislocations would give an angle of $0^{\circ}$, with the creation of interfacial segments parallel to the interface.

In contrast to the $\mathrm{Al} / \mathrm{SiO}_{\mathrm{x}}$ interface, copper films deposited on sapphire possess a crystalline/crystalline interface with an epitaxial relationship (Dehm et al., 2002). Thermal cycling similar to those performed on $\mathrm{Al} / \mathrm{SiO}_{\mathrm{x}}$ have been performed on the $\mathrm{Cu} / \mathrm{Al}_{2} \mathrm{O}_{3}$ system. Figure 10 shows a common relaxation mechanism of the copper layer at the end of a thermal cycle: dislocations are nucleated by means of a dislocation source located in the film (or strip) thickness (Fig. 10a). The dislocation segments that are emitted escape via the film surface on one end (top of the figure) or are blocked at the sapphire interface on the other (Fig. 10b). This results, for instance, in the formation of pile-ups, as seen in Figure 10b where five dislocations stack against the interface. Also, note that interfacial dislocations are visible in Figure 10b. Occasionally, some of the dislocations piling up against the interfacial dislocation network can be incorporated into this network after long waiting times. During heating, some of the dislocations in this network are also directly emitted into the strip thickness and sweep to the free surface. The absorption/emission of dislocations by the sapphire $/ \mathrm{Cu}$ interface is a process that proves to be, at least partially, repeatable. The general trend when performing successive thermal cycling is that the dislocation pile-ups formed during cooling are just undone when heating again. Such experiments clearly prove that this crystal/crystal interface repels dislocations inside the metal layer, whereas the $\mathrm{Al} / \mathrm{SiO}_{\mathrm{x}}$ interface,

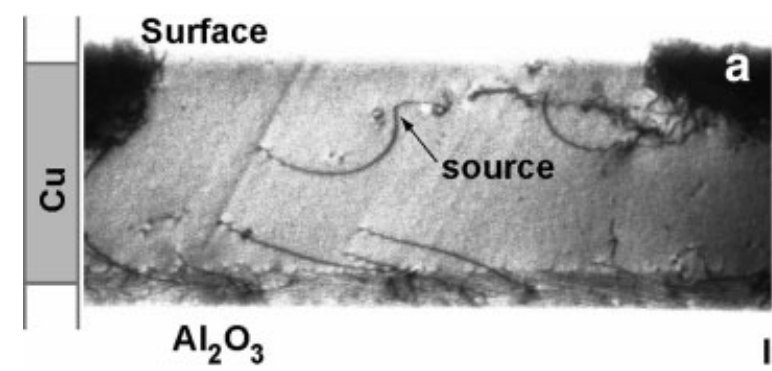

Fig. 10. Repulsive dislocation-interface interaction in a 900-nmthick $\mathrm{Cu}$ film deposited on sapphire and observed in cross-section. Still pictures taken at $20^{\circ} \mathrm{C}$ after in situ cycles up to $450^{\circ} \mathrm{C}$. Figure (a) has been taken at the beginning of the relaxation at room tempera- ture, figure (b) several minutes after. Dislocations $\left(d_{1-5}\right)$ emitted by the source pile-up against the interface, materialized by interfacial dislocations. 


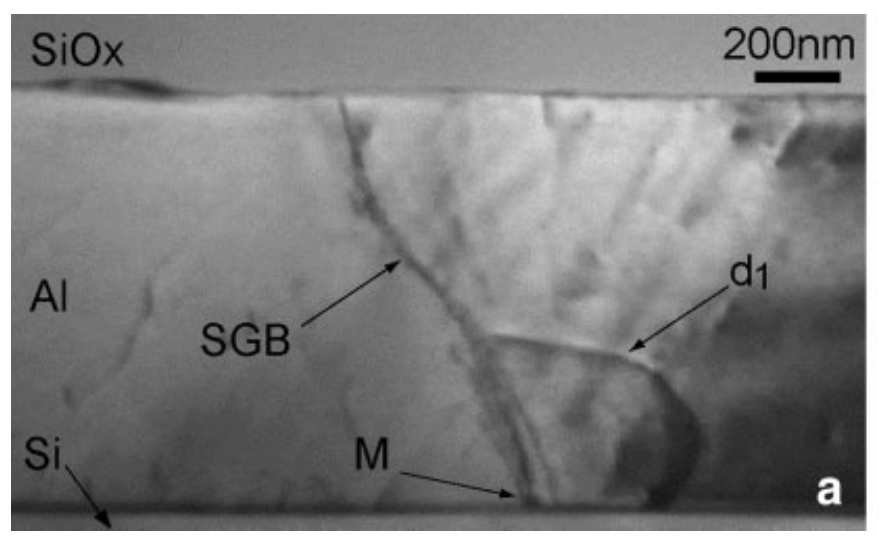

Fig. 11. Dislocation nucleation (a) at a subgrain boundary and (b) at the $\mathrm{Al} / \mathrm{SiO}_{\mathrm{x}}$ interface. In situ TEM stills extracted from a video sequence taken during the thermal cycling of a passivated $1-\mu \mathrm{m} \mathrm{Al}$ film. The first loop $\left(d_{1}\right)$ is emitted from the middle of the subgrain boundary (SGB) and then escapes from the Al strip. More active

which has a crystal/amorphous nature, acts as a dislocation sink.

Local stress measurement with the help of the Orowan equation is also possible when curved dislocations are moving, as it is the case of the source in Figure 10a. In order for the dislocation to move, the local resolved shear stress has to be larger than the dislocation line tension $\tau$ :

$$
\sigma>\tau=\frac{\mu b}{R}
$$

where $\mu$ is the shear modulus of the material $\left(\mu_{\mathrm{Al}}=26\right.$ $\left.\mathrm{GPa}, \mu_{\mathrm{Cu}}=48 \mathrm{GPa}\right), b$ is the Burgers vector amplitude $\left(b_{\mathrm{Al}}=0.29 \mathrm{~nm}, b_{\mathrm{Cu}}=0.26 \mathrm{~nm}\right)$, and $R$ is the radius of curvature of the dislocation in its glide plane. From curved dislocation segments in Figures $8 \mathrm{a}$ and 10a, a critical resolved shear stress of about $25 \mathrm{MPa}$ is found for $\mathrm{Al}$ and $40 \mathrm{MPa}$ for $\mathrm{Cu}$, which is in good agreement with the biaxial stresses measured with wafer curvature technique for the given temperatures. Note that the stress measurement by the dislocation curvature technique is not accurate enough to verify the $20 \%$ stress deficit between the wedge configuration and the blanket film on its substrate (Fig. 5).

\section{Plasticity Controlled by Dislocation Nucleation}

We have seen that in $\mathrm{Cu}$ films, the dislocation density remains sufficient to carry the small plastic strains imposed in thermal experiments. In $\mathrm{Al}$ films, this density is either initially insufficient (films thinner than $200 \mathrm{~nm}$ ) or excessively reduced after thermal cycling. In both cases, an efficient stress relaxation requires the creation of new dislocations. Figure 11 describes a nucleation process observed in a $1-\mu \mathrm{m}$ passivated $\mathrm{Al}$ film. The first nucleation occurs at a SGB (Fig. 11a) but most of the shearing events originate at the intersection between the $\mathrm{SGB}$ and the $\mathrm{Al} / \mathrm{Si}$ interface (point $\mathrm{M})$. In Figure $11 \mathrm{~b}$, one of the multiple loops that sheared the Al strip and created the thick slip traces (Tr.) remains after an avalanche (very fast occurrence of many dislocation loops expanding within one video

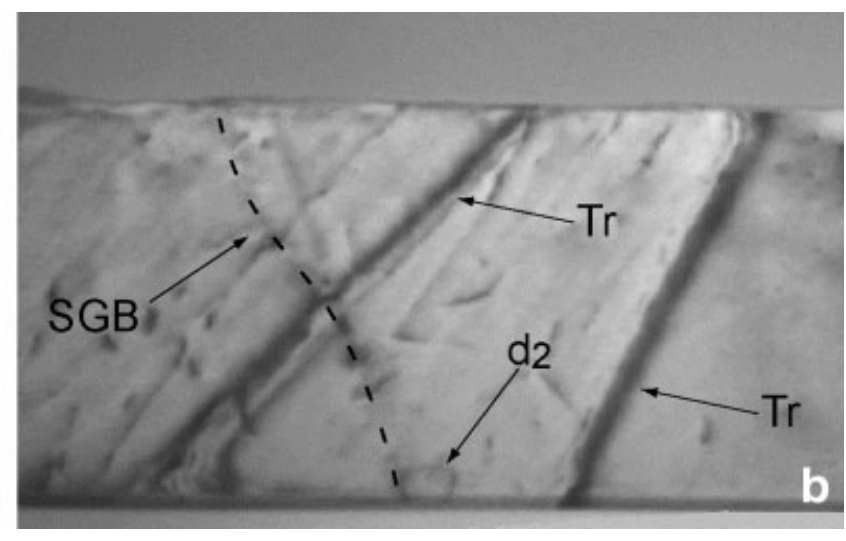

nucleation takes place at the intersection between $\mathrm{SGB}$ and the $\mathrm{Al} / \mathrm{Si}$ interface (point $\mathrm{M}$ ) where a thin $\mathrm{SiO}_{\mathrm{x}}$ layer is present. These emissions create thick slip traces (Tr). $d_{2}$ is a dislocation loop that will expand between the marked slip traces.

frame). Measuring the radius of curvature of $d_{2}(20-30$ $\mathrm{nm}$ ) in Figure 11b leads to a resolved stress level of about 30-40 MPa, higher than what is measured with the wafer curvature method on plain wafers. At this point in thermal cycling where the dislocation density has significantly dropped, stress relaxation is therefore more difficult.

In thinner films, very few grains contain dislocations, and scarce changes of the microstructure are noted. Dislocation sources have been observed neither at the interface nor at the grain boundaries. A possible reason could be that all the grain boundaries are perpendicular to the interface at variance with the situation of Figure 11 where the SGB is inclined. These repeated observations suggest that an inclined grain boundary is a much more favorable configuration for dislocation nucleation. Figure 12 shows a sequence in which the absence of dislocation sources is compensated by plastic deformation that is carried out by GB motion. This sequence is taken in a $200-\mathrm{nm}$-thick $\mathrm{Al}$ film in which all the boundaries are perpendicular to the interface. The complete and rapid grain collapse is due to the opposite motion of both its left and right boundary. Those GBs are perpendicular to the film interface, but inclined with respect to the cross-sectional foil, as indicated by white and black fringes. These GBs remain perpendicular to the interface throughout their displacement, with a slight curvature toward the direction of motion. This GB motion occurs without any visible dislocation processes or appearance of slip lines. Note that the velocity of this displacement is on the order of $50-100 \mathrm{~nm} / \mathrm{s}$ and that the grain boundary retains its near $90^{\circ}$ inclination to both the surface and interface during this displacement. This suggests that the moving GB is equally hindered by the free surface of the Al film and its interface with the silicon oxide. The impact of such displacements on plastic relaxation is, however, more difficult to quantify than with dislocations.

\section{DISCUSSION}

In this section, we will discuss, in turn, the relevance of the in situ observations relative to "macroscopic" 

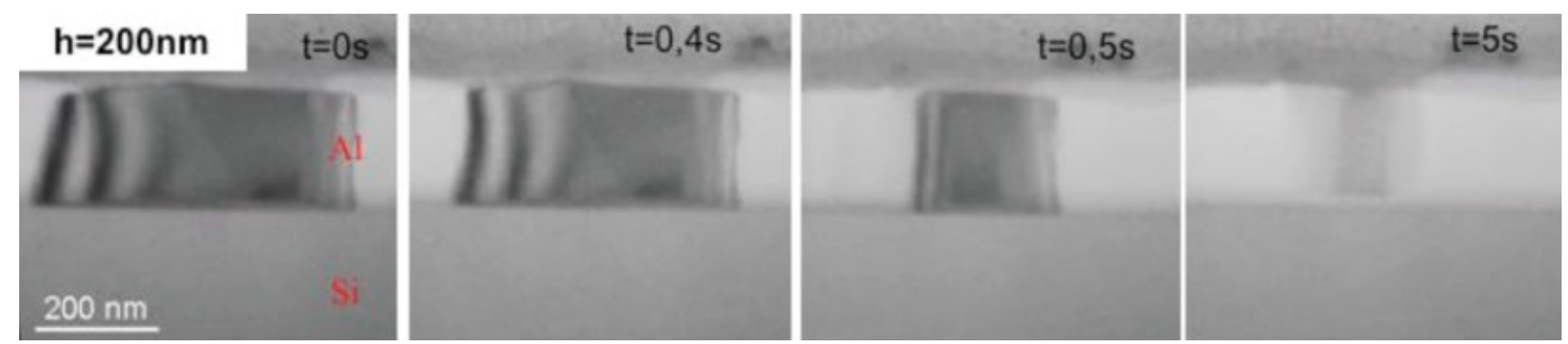

Fig. 12. Sequence of video stills extracted from an in situ TEM sequence taken at $410^{\circ} \mathrm{C}$. A grain boundary in a 200-nm-thick unpassivated Al film collapses rapidly by the opposite motion of its right and left GB. [Color figure can be viewed in the online issue, which is available at www.interscience. wiley.com.]

tests, how they address the current thin-film deformation theories, and what technical developments could be envisaged.

\section{In Situ TEM Versus Wafer Curvature Experiments}

As is always the case for in situ TEM, the significance of the observations relative to the original sample is of prime concern. The plan-view configuration (Fig. 2) leaves the film unaffected, but the thickness and the geometry of the wafer remaining under the metal film are difficult to control during sample preparation. The problem becomes complex if a thick amorphous layer (oxide, nitride) is inserted between the metallic film and the substrate. The plan-view configuration will only leave a part of this amorphous layer, which is difficult to determine easily in the TEM. The remaining thickness under the metal layer plays a large role in the curvature of the sample, and therefore on the stress transmitted to the film [see Eq. (1) and (Cabie, 2005; Cabie et al., 2004)]. The advantage of this technique is, however, that heating cycles will produce a biaxial stress state, similar to what occurs with the initial films on substrates. The values of stresses are not well known, but if the dimple is small compared with the rest of the sample, then its curvature will depend only on the thick parts and should be close to those encountered in macroscopic samples.

This in situ method is the most widely employed to study the relaxation modes of thin metal films on substrate. It was the first to reveal a possible transition in the plastic relaxation mechanisms in $\mathrm{Cu}$ films: Balk et al. found that, below $200 \mathrm{~nm}$, parallel glide of dislocations took place in polycrystalline $\mathrm{Cu}$ films deposited on nitrided Si substrates (Balk et al., 2003). By observing $\mathrm{Al}$ films on oxidized substrates that have been cycled outside the TEM, Müllner and Arzt also pointed out that dislocations at the interface between the $\mathrm{Al}$ film and the oxide could spontaneously disappear (Müllner and Arzt, 1998). This observation partially invalidates the Nix-Freund model, in which the increase in yield stress was attributed to the trailing of interfacial dislocations. In a former work, we also verified that the dislocation density decrease also occurred in samples that were cycled outside the TEM, and was not uniquely due to the shape of the in situ sample (Legros et al., 2002). In parallel, the absence of trailing interfacial dislocations renders it difficult to measure the local stress state from dislocation curvature during in situ TEM [Eq. (3)]. If neither the free surface nor the interface with the substrate provides a sufficient obstacle for dislocation motion, a threading dislocation segment will shear the metal film with both ends nearly perpendicular to the interface, and with a curvature much larger than the film thickness. This situation was exacerbated for thinner films on amorphous substrates because very few movements of threading dislocations were observed, and among them, almost no curved dislocations could be found. The lack of plasticity in ultrathin films is also linked to the very limited amount of plastic deformation per cycle (on the order of $1 \%$ or lower (Legros, 2006)).

\section{In Situ TEM Versus Thin-Film Plasticity Theories}

The interaction between the threading dislocations and the interfaces is of prime importance to endorse or refute the Nix-Freund threading dislocation theory of increased thin film strength with decreased thickness. Such analysis can be better performed using cross-sectional in situ experiments where the interface is viewed end-on (Figs. 4, 5b, 6-12). Qualitatively, it can be seen that dislocations form an acute angle with the amorphous (or incoherent) interface (Fig. 8), which is a first indication that it does not leave a trailing interfacial segment. The possibility of an invisible interfacial segment could be ruled out, because at the magnification we are working at, the line tension of the dislocation would prevent the formation of a very small bowed segment near the interface that we could not see. Also, when looking at dynamic sequences, such as the one in Figure 8, a loop expanding near the interface disappears in less than a video frame $(0.04 \mathrm{~s})$. This is much faster than the waiting time of a loop between two obstacles inside the Al film (Figs. 8c and 8d), but also faster than the time needed to erase the slip traces at the free surfaces of the Al strip (Fig. 11) in the plastic regime $\left(150-400^{\circ} \mathrm{C}\right)$.

Systematically measuring the angle made by a moving dislocation segment with the incoherent interface (Fig. 9) provides a finer analysis (Legros et al., 2005a). If the interface acted as a perfect free surface, the angle would be close to $90^{\circ}$ for very thin films, and would slightly deviate from this value for thicker films. If the interface was impenetrable to dislocations, which is expected when comparing the relative stiffness of $\mathrm{Al}$ 
and $\mathrm{SiO}_{\mathrm{x}}$ (Ovecoglu et al., 1987), then the threading dislocation should create and trail interfacial segments parallel to the interface (Nix, 1998), leading to an angle of $0^{\circ}$. Here, we observe an average angle of $60^{\circ}$ and no angle smaller than $20^{\circ}$ has been measured. Note that even a grain boundary can move with an angle $\theta$ close to $90^{\circ}$, as exemplified in Figure 12.

On the contrary, the $\mathrm{Cu} /$ sapphire interface proved to be a strong obstacle to dislocations, as demonstrated by the pile-up of Figure 10b. Such pile-ups could eventually force the first dislocation into the interfacial dislocation network, which also proves that the interface is an obstacle that can be overcome. Similar observations of a threading dislocation repelled by a sapphire substrate can be found for Al strips (Inkson et al., 2002). Also, no complete dislocation shortage was observed in these $\mathrm{Cu}$ strips, and up to six consecutive thermal cycles could be performed without exhausting the motion of threading dislocations. This supply of dislocations was ensured by the activation of sources (Fig. 10a) and by the emission of interfacial dislocations.

For a given thickness, the measured normalized room temperature stress is therefore higher for an $\mathrm{Al}$ or $\mathrm{Cu}$ film deposited on a $\mathrm{Si}$ substrate with an amorphous interface than an analogous film deposited on sapphire (Fig. 1b). If the dislocation/interface interaction was the cause of such discrepancy, we should observe the contrary because the sapphire is a much harder material compared with $\mathrm{Si}, \mathrm{SiO}_{\mathrm{x}}$, or $\mathrm{Si}_{3} \mathrm{~N}_{4}$. Here, the softer interface corresponds to the stronger film. Therefore, the strength of metallic films deposited on oxidized $\mathrm{Si}$ substrates cannot be explained by the Nix-Freund threading dislocation theory, at variance from epitaxial films on sapphire (Dehm et al., 2003) or of semiconductor layers (Freund and Jonsdottir, 1993). The very high stress displayed by metallic films with an amorphous interface, at least in the micron range $(>400 \mathrm{~nm})$, is rather rationalized by the lack of dislocations and dislocation sources. As seen in this study (Fig. 6), the $\mathrm{Al} / \mathrm{SiO}_{\mathrm{x}}$ interface proves a very efficient sink for dislocations or even low angle GBs, and this interface does not promote dislocation nucleation. Figure 11 points to the difficulty of creating fresh dislocations, and when particular conditions are respected (presence of an inclined GB at the interface), the accumulated stress leads to an avalanche of dislocations. This observation confirms that the dislocation-based relaxation of the stress depends on the generation and not on the propagation of existing dislocations.

A final question raised by the plot in Figure $1 b$ is the existence of a plateau regime where the room temperature stress of metallic films on Si remains approximately constant or even decreases below a critical thickness. The graph in Figure 1b suggests that this critical thickness lies at around $400 \mathrm{~nm}$ for many metals, but recent thermal cycling experiments carried out to $-100^{\circ} \mathrm{C}$ (Eiper et al., 2007) instead place this limit at around $200 \mathrm{~nm}$. In fact, as the amount of strain imposed during a thermal cycle decreases with the film thickness, thinner films are not plastically deformed for a given temperature range (Wiederhirn 2007). Their yield stress is therefore not known but is likely to reach a limit as the thickness diminishes. This stress limit, probably reached below $200 \mathrm{~nm}$, should call for a change in deformation mechanism between thick and thinner films. The following paragraphs discuss the insight brought by in situ TEM experiments on this topic.

As mentioned earlier, thermal cycles performed on thin and ultrathin $\mathrm{Cu}$ films observed in plan view revealed that below $200 \mathrm{~nm}$, parallel glide (Balk et al., 2003) took over regular threading dislocations in accommodating shear. This dislocation propagation mode does not relieve the applied strain and was therefore considered as evidence of grain boundary diffusion. In very thin $\mathrm{Cu}$ films, the plastic relaxation would be fulfilled by the extrusion of excess atoms to the surface during the compressive phase and the incorporation of these atoms during tensile phases of a thermal cycle. The paths of diffusion are grain boundaries perpendicular to the surface (Gao et al., 1999). This diffusionbased mechanism could explain the reversible emission and absorption of parallel dislocations at GBs, uniquely present for ultrathin polycrystalline layers of metals that do not form a native oxide layer. For films thicker than $200 \mathrm{~nm}$, threading dislocations were observed, as described in the Nix-Freund model (Nix, 1998; Thompson, 1993). Parallel dislocation glide was therefore understood as the signature of a transition between a threading dislocation-based mechanism operating in thicker films and a diffusion-based mechanism operating in polycrystalline $\mathrm{Cu}$ films thinner than $200 \mathrm{~nm}$. Such a mechanism is therefore not expected to operate in $\mathrm{Al}$ films that do form a native alumina layer at their free surface. However, Figure 12 suggests that an alternate mechanism is possible in ultrathin $\mathrm{Al}$ films that are initially dislocation-free. This sequence describes the collapse of a grain by the opposite motion of its two boundaries. The reduction of the number of $\mathrm{GBs}$ in a film could relieve some of the compressive strain (Greiser et al., 2001), but the process is irreversible and cannot achieve stress relaxation in tension. In addition, this mechanism can only release a fraction of the applied stress. More generally, GB-based plasticity (Legros et al., 2008b) has been known for a long time and different models are available to account for the strain accompanying a GB displacement. Purely geometrical models predict a shear that can be of the same order as the GB displacement (Cahn and Taylor, 2004), whereas short-range diffusion-based models (Balluffi and Cahn, 1981; Mompiou et al., 2008) induce smaller strains. Here, additional experiments are needed, where the crystallographic orientations of the moving GB would be known (Mompiou et al., 2007), to fully compare our experiments with existing theories.

\section{Alternative In Situ TEM Methods for Thin Films on Substrates}

Metal films deposited on stretchable polymer substrates (Fig. 3) provide a good alternative to the strain limitation inherent to the thermal cycles based on differential CTE between the film and its substrate. There, stress-strain curves can be established with the help of image correlation and X-rays to measure the strain and stress in the film. Recent experiments performed on $\mathrm{Au}$ films on polyimide revealed size effects on the yield stress $\sigma_{\mathrm{y}}$ of these films (Oh et al., 2007). A linear increase of $\sigma_{\mathrm{y}}$ was measured above $80 \mathrm{~nm}$, whereas films thinner than $80 \mathrm{~nm}$ had a constant yield stress. Employing a new technique based on FIB carv- 


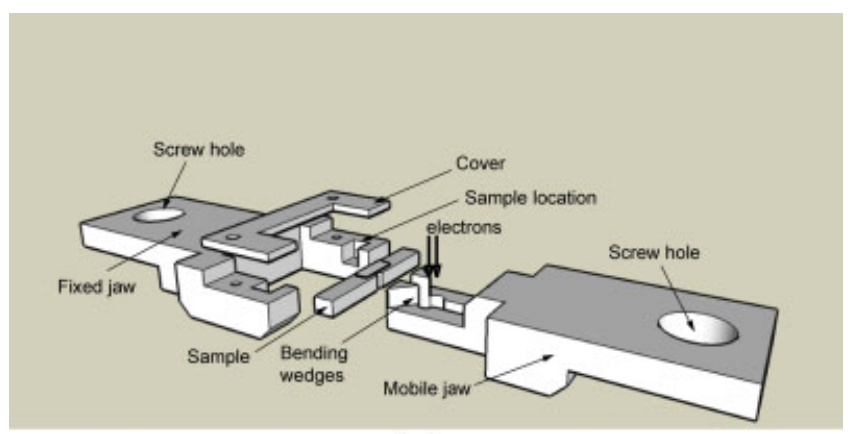

(a)

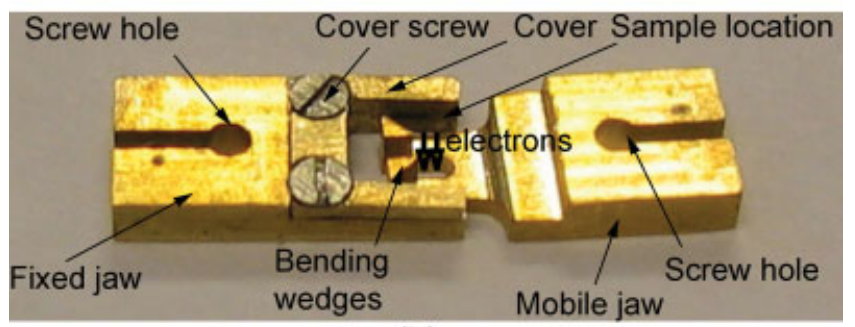

(b)

Fig. 13. Bending jig designed to transform uniaxial straining into bending motion inside a TEM holder. (a) 3D Sketch of the sample, cover, mobile and fixed jaws, (b) photograph of an actual set up. Each jaw is $5 \mathrm{~mm}$ long and $3 \mathrm{~mm}$ large. Cover screws have been omitted in (a), sample is not represented in (b). Electron path is shown in both figures. [Color figure can be viewed in the online issue, which is available at www.interscience.wiley.com.]

ing of metal film on polymer substrate (Fig. 3 (Dehm et al., 2006), in situ TEM straining experiments showed that this change in the slope of the curve $\sigma_{\mathrm{y}}=$ $f\left(1 / t_{f}\right)$ (Fig. $\left.1 b\right)$ was due to a trade between perfect dislocations in thick films to partial dislocation and twinning in thin $\mathrm{Au}$ films. If the transition from perfect to partial dislocations can be rationalized in term of nucleation energy (lower for smaller Burgers vector), the reason why $\sigma_{\mathrm{y}}$ seems constant below $80 \mathrm{~nm}$ is still an open question. Here, the role of the interface is assumed to be limited as the polymer substrate does not provide a strong obstacle for dislocations to escape the Au film.

The main disadvantage of the experiments based on the different CTE between the film and the substrate is the tight correlation between stress and temperature. When diffusive mechanisms such as the disappearance of dislocations at incoherent interfaces, or GB diffusion are involved, it would be helpful to sort the effects of both processes. A second drawback is the limited strain due to a small difference in CTE or to the high yield stress of thinner films. It prevents a full investigation of the plastic relaxation mechanism in many systems. Metal film on polymer is an alternative, but the interface effect is weakened because the film is stiffer than the substrate. Preliminary bending experiments were thus undertaken to provide a way to observe the separated effects of stress and/or temperature on the dislocation/interface interactions in a cross-sectional sample. The first step consisted of converting a heatingstraining holder into a bending stage. This loading configuration is realized by the special jaws sketched in

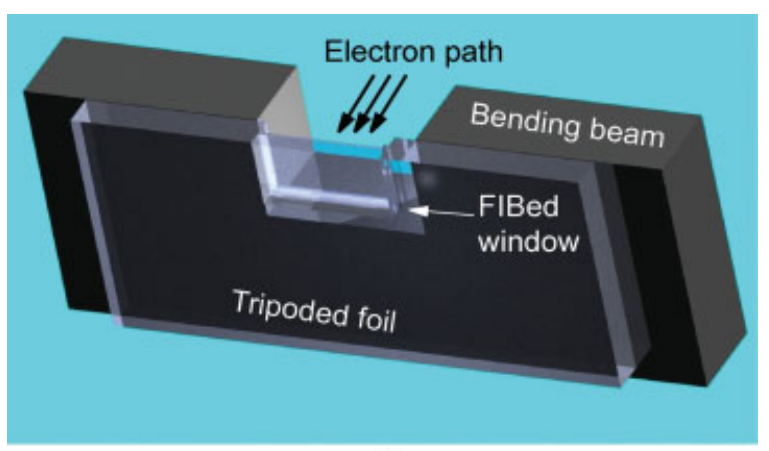

(a)

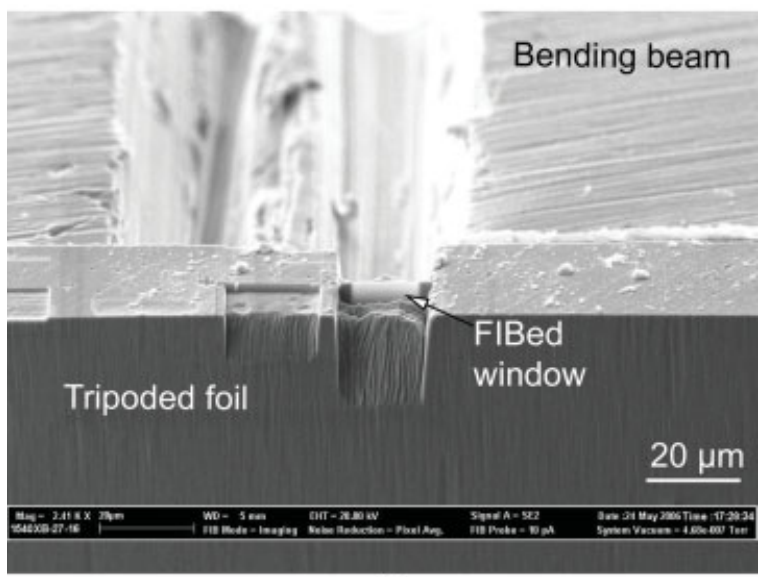

(b)

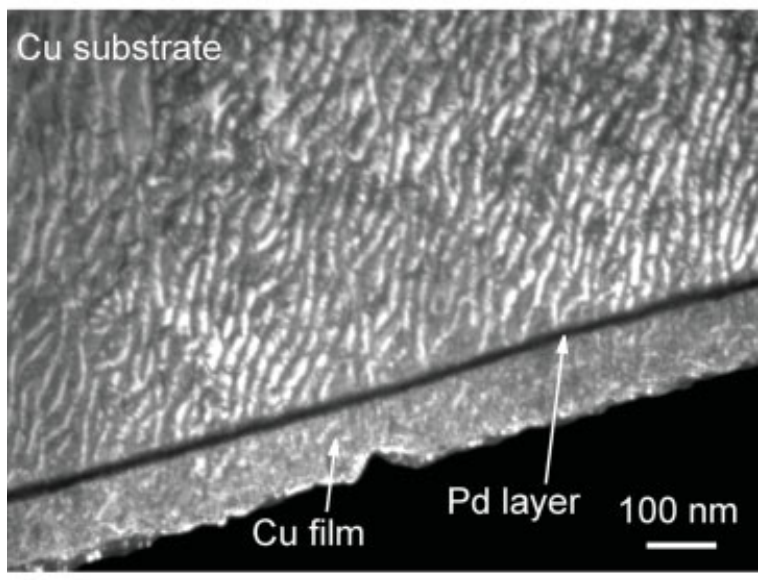

(c)

Fig. 14. Bending sample (a) sketch of the tripoded and FIBed sample glued onto the bending beam (not to scale), (b) SEM picture of the actual sample, (c) TEM picture of the electron transparent window in a $\mathrm{Cu} / \mathrm{Pd} / \mathrm{Cu}$ sample (processed by M. Verdier, SIMAP, Grenoble). [Color figure can be viewed in the online issue, which is available at www.interscience.wiley.com.]

Figure 13. In this set up, a beam of $\sim 0.2 \times 0.2 \times 1.5$ $\mathrm{mm}^{3}$ constructed from a deformable material can be inserted in the sample location in the fixed jaw and held in place with a cover. The mobile jaw is inserted behind this bar and the bending wedges are designed to put the sample in tension in the zone where it is elec- 
tron transparent, as in a four-point bending test. The sample is sketched in Figure 14a. It consists of a deformable bending beam with a notch to let the electron beam pass through the electron transparent zone of the actual sample that is simply glued on the bending beam. A window is carved with the FIB into a $20-\mu \mathrm{m}-$ thick foil prethinned with the tripod technique, in front of the notch. Both the bending beam and the FIBed electron transparent window that have been milled down to a thickness of $200 \mathrm{~nm}$ are visible in Figure $14 \mathrm{~b}$. Figure $14 \mathrm{c}$ is a TEM picture of the sample used for this first experiment: a $100-\mathrm{nm} \mathrm{Cu}$ film deposited by molecular beam epitaxy after $10 \mathrm{~nm}$ of $\mathrm{Pd}$ was layered onto a polished $\mathrm{Cu}$ substrate. The Pd layer provides an interface to separate the mechanical response of the $\mathrm{Cu}$ layer from the $\mathrm{Cu}$ substrate. Similar to cross-sectional samples of $\mathrm{Cu}$ or $\mathrm{Al}$ films previously shown, the $\mathrm{Cu}$ layer stands now as a thin strip or nanowire with a section of $100 \times 200 \mathrm{~nm}^{2}$. Experiments performed with this new set up are underway.

\section{CONCLUSIONS}

Several in situ TEM techniques available to deform thin metallic films or strips on substrates have been reviewed. Thermal cycling, which takes advantages of the differences between the CTE of the metallic film and that of the hard substrate ( $\mathrm{Si}$, sapphire, etc.), is a common method for the investigation of film strength and can be reproduced in situ.

i. For thinner films, plan-view in situ TEM offers the advantage of faithfully reproducing the biaxial stress state of the film. This configuration is limited by electron transparency requirements and thus is devoted to ultrathin films.

ii. Cross-sectional samples are not limited by the film thickness, but they form one-dimensional strips instead of films. Thermal cycling can also be applied successfully to these "nanowires" on substrate, and allow for better dislocation-interface interaction analysis. Attention should be paid to the fact that the stress in these wires is $20 \%$ smaller than in the blanket film and that the stress tensor becomes uniaxial instead of biaxial.

These analyses showed that metal/amorphous interfaces acted like dislocation sinks that cause the rapid depletion of dislocations in metal films on oxidized $\mathrm{Si}$ substrates. In contrast, crystalline/crystalline interfaces served as dislocation repellants as in the case of $\mathrm{Cu}$ films on sapphire. Nucleation of fresh dislocations in $\mathrm{Al}$ films proved very difficult, whereas a sufficient dislocation density for plasticity remained in $\mathrm{Cu}$ films. This difference in interfacial behavior is echoed in the larger strength demonstrated by films with incoherent interface when compared with epitaxial films. As a conclusion, the larger strength of films with incoherent interfaces appears to be the result of dislocation depletion.

In situ TEM also provides insight about the change in plastic deformation mechanisms suggested by the saturation of the strength of thinner films:

iii. In films thinner than $200 \mathrm{~nm}$, the initial dislocation density was very low and scarce dislocation movement could be observed. Fast grain boundary dis- placements were captured and could signal a transition between dislocation- and GB-based relaxation mechanisms.

iv. Au films deposited on stretchable polyimide substrates transition from perfect to partial dislocation shear below $80 \mathrm{~nm}$.

Further experiments using an in situ TEM bending stage are underway. Their purpose is to induce stress in a strip of material on its substrate while separately varying the applied strain and the temperature.

\section{ACKNOWLEDGMENTS}

ML thanks J.-P. Feiereisen for his simulation of stress in thin films, G. Dehm, R. Spolenak, P. Gruber, S.H. Oh, John T. Balk, E. Arzt, F. Mompiou, and K. Hemker for continuous stimulating discussions. DSG acknowledges support from an Alexander von Humboldt Postdoctoral Fellowship.

\section{REFERENCES}

Abermann R, Koch R. 1985. The internal stress in thin silver, copper and gold films. Thin Solid Films 129:71-78.

Ames I, d'Heurle F, Horstmann RE. 1970. Reduction of electromigration in aluminum films by copper doping. IBM J Res Dev 14:461463.

Arzt E. 1998. Size effects in materials due to microstructural and dimensional constraints: a comparative review. Acta Mater 46:5611-5626.

Balk TJ, Dehm G, Arzt E. 2003. Parallel glide: unexpected dislocation motion parallel to the substrate in ultrathin copper films. Acta Mater 51:4471-4485.

Balluffi RW, Cahn JW. 1981. Mechanism for diffusion induced grain boundary migration. Acta Metall 29:493-500.

Bostrom O. 2001. Wafer shape control - Study of the reactivity in $\mathrm{Ti} /$ Al dual layers and its effect on the stress [Ph.D.]. Marseille, France: Université d'Aix-MarseilleIII, Faculté des Sciences et Techniques de Saint-Jérôme. 155 p.

Cabie M. 2005. Contribution à l'étude des contraintes par la méthode de la courbure dans les systèmes épitaxiés [Ph.D.]. Toulouse, France: Université Paul Sabatier. 168 p.

Cabie M, Ponchet A, Rocher A, Paillard V, Vincent L. 2004. Transmission electron microscopy and Raman measurements of the misfits stress in a Si tensile strained layer. Appl Phys Lett 84:870-872.

Cahn JW, Taylor JE. 2004. A unified approach to motion of grain boundaries, relative tangential translation along grain boundaries, and grain rotation. Acta Mater 52:4887-4898.

Chaudari P. 1979. Plastic properties of polycristalline thin films on a substrate. Philos Mag A 39:507-516.

Dehm G, Balk TJ, Edongue H, Arzt E. 2003. Small-scale plasticity in thin $\mathrm{Cu}$ and $\mathrm{Al}$ films. Microelectron Eng 70:412-424.

Dehm G, Inkson BJ, Balk TJ, Wagner T, Arzt E. 2001a. Influence of film/substrate interface structure on plasticity in metal films. In: Kraft O, Schwarz KW, Baker SP, Freund LB, editors. San Francisco. Mat Res Soc Symp Proc p 1-12.

Dehm G, Legros M, Heiland B. 2006. In-situ TEM straining experiments of $\mathrm{Al}$ films on polyimide using a novel FIB design for specimen preparation. J Mater Sci 41:4484-4489.

Dehm G, Weiss D, Arzt E. 2001b. In situ transmission electron microscopy study of thermal-stress-induced dislocations in a thin $\mathrm{Cu}$ film constrained by a Si substrate. Mater Sci Eng A 309-310:468472.

Eiper E, Keckes J, Martinschitz KJ, Zizak I, Cabie M, Dehm G. 2007. Size-independent stresses in $\mathrm{Al}$ thin films thermally strained down to $-100^{\circ}$ C. Acta Mater 55:1941-1946.

Flinn PA, Gardner DS, Nix WD. 1987. Measurements and interpretation of stress in Aluminum-based metallization as a function of thermal history. IEEE Trans Electron Dev 34:689-699.

Freund LB. 1987. The stability of a dislocation threading a strained layer on a substrate. J Appl Mech 54:553-557.

Freund LB, Jonsdottir F. 1993. Instability of a biaxially stressed thin film on a substrate due to material diffusion over its free surface. J Mech Phys Solids 41:1245-1264. 
Frost HJ, Ashby MF. 1982. Deformation mechanisms maps. Oxford: Pergamon Press.

Gao H, Zhang L, Nix WD, Thompson CV, Arzt E. 1999. Crack-like grain-boundary diffusion wedges in thin metal films. Acta Mater 47:2865-2878.

Gerth D, Katzer D, Schwarzer RA. 1994. The influence of local thermomechanical stress on grain growth in thin $\mathrm{Al}-1 \% \mathrm{Si}$ layers on $\mathrm{SiO}_{2} / \mathrm{Si}$ substrates. Phys Status Solidi A 146:299-316.

Gianola DS, Van Petegem S, Legros M, Brandstetter S, Van Swygenhoven H, Hemker KJ. 2006. Stress-assisted discontinuous grain growth and its effect on the deformation behavior of nanocrystalline aluminum thin films. Acta Mater 54:2253-2263.

Greer JR, Oliver WC, Nix WD. 2005. Size dependence of mechanical properties of gold at the micron scale in the absence of strain gradients. Acta Mater 53:1821-1830.

Greiser J, Mullner P, Arzt E. 2001. Abnormal growth of "giant” grains in silver thin films. Acta Mater 49:1041-1050.

Inkson BJ, Dehm G, Wagner T. 2002. In situ TEM observation of dislocation motion in thermally strained $\mathrm{Al}$ nanowires. Acta Mater 50:5033-5047.

Kiener D, Grosinger W, Dehm G, Pippan R. 2008. A further step towards an understanding of size-dependent crystal plasticity: In situ tension experiments of miniaturized single-crystal copper samples. Acta Mater 56:580-592.

Kobrinsky MJ, Thompson CV. 2000. Activation volume for inelastic deformation in polycrystalline Ag thin films. Acta Mater 48:625633.

Kubovy A, Janda M. 1977. The influence of residual gas pressure on the stress in aluminium films. Thin Solid Films 42:169-173.

Legros M. 2006. Relaxation plastique des couches minces métalliques par dislocations et défauts étendus. In: Mouis M, editor. Contraintes en microelectronique: Hermes. pp 229-260.

Legros M, Dehm G, Arzt E, Balk TJ. 2008a. Observation of Giant Diffusivity Along Dislocation Cores. Science 319:1646-1649.

Legros M, Dehm G, Balk TJ. 2005a. In-Situ TEM study of plastic stress relaxation mechanisms and interface effects in metallic films. In: Buchheit TE, Minor AM, Spolenak R, Takashima K, editors. Mat Res Soc Symp Proc San Francisco. p 237-247.

Legros M, Dehm G, Balk TJ, Arzt E, Bostrom O, Gergaud P, Thomas O, Kaouache B. 2003. Plasticity-related phenomena in metallic films on substrates. In: Zbib HM, Lassila DH, Levine LE, Hemker KJ, editors. Mat Res Soc Symp Proc San Francisco. p 63-74.

Legros M, Dehm G, Keller-Flaig RM, Arzt E, Hemker KJ, Suresh S. 2000a. Dynamic observation of Al thin films plastically strained in a TEM. Mat Sci Eng 309-310:463-467.

Legros M, Elliott BR, Rittner MN, Weertman JR, Hemker KJ. 2000b. Microsample tensile testing of nanocrystalline metals. Philos Mag A (Physics of Condensed Matter: Structure, Defects and Mechanical Properties) 80:1017-1026.

Legros M, Gianola DS, Hemker KJ. 2008b. In situ TEM observations of fast grain-boundary motion in stressed nanocrystalline aluminum films. Acta Mater 56:3380-3393.
Legros M, Hemker KJ, Gouldstone A, Suresh S, Keller-Flaig RM, Arzt E. 2002. Microstructural evolution in passivated Al films on Si substrates during thermal cycling. Acta Mater 50:3435-3452.

Legros M, Kaouache B, Gergaud P, Thomas O, Dehm G, Balk TJ, Arzt E. 2005 b. Pipe diffusion ripening of Si precipitates in $\mathrm{Al}-0,5 \% \mathrm{Cu}$ $1 \%$ Si thin films. Philos Mag A 85:3541-3552.

Leung OS. 2001. Studies in the strenghtening mechanisms of thin polycristalline gold films [Ph.D.]. Stanford: Stanford University. $170 \mathrm{p}$.

Matthews JW, Blakeslee AE. 1974. Defects in epitaxial multilayers: I Misfit dislocations. J Cryst Growth 27:118-125.

Matthews JW, Blakeslee AE. 1975. Defects in epitaxial multilayers: II. Dislocation pile-ups, threading dislocations, slip lines and cracks. J Cryst Growth 29:273-280.

Mompiou F, Legros M, Caillard D. 2008. Stress assisted grain growth in ultrafine and nanocrystalline aluminum revealed by in-situ TEM. In: Friesen RCC C, Hodge A, Warren OL, (editors). San Francisco. Materials Research Society. p U09-U04.

Müllner P, Arzt E. 1998. Observation of dislocation disappearance in aluminum thin films and consequences for thin film properties. In: Cammarata R, Nastasi M, Busso E, Oliver W, editors. Boston, MA. Mat Res Soc Symp Proc 505, Warrendale, PA. p 149-154.

Nicola L, Van der Giessen E, Needleman A. 2005. Size effects in polycrystalline thin films analyzed by discrete dislocation plasticity. Thin Solid Films 479:329-338.

Nix WD. 1989. Mechanical properties of thin films. Metall Trans A 20A:2217-2245.

Nix WD. 1998. Yielding and strain hardening of thin metal films on substrates. Scr Mater 39:545-554.

Oh SH, Legros M, Kiener D, Gruber P, Dehm G. 2007. In situ TEM straining of single crystal Au films on polyimide: Change of deformation mechanisms at the nanoscale. Acta Mater 55:5558-5571.

Ovecoglu ML, Doerner MF, Nix WD. 1987. Elastic interactions of screw dislocations in thin films on substrates. Acta Metallurgica 35:2947-2957.

Schmidt TK, Balk TJ, Dehm G, Arzt E. 2004. Influence of tantalum and silver interlayers on thermal stress evolution in copper thin films on silicon substrates. Scr Mater 50:733-737.

Stoney GG. 1909. The Tension of Metallic Films Deposited by Electrolysis. Proc R Soc Lond A 82:172-175.

Thompson CV. 1993. The yield stress of polycristalline thin films. J Mater Res 8:237-238.

Thouless MD. 1995. Modeling the development and relaxation of stresses in films. Annu Rev Mater Sci 25:69-96.

Van Swygenhoven H, Derlet PM, Froseth AG. 2006. Nucleation and propagation of dislocations in nanocrystalline fcc metals. Acta Mater 54:1975-1983.

Weihnacht V, Bruckner W. 2001. Dislocation accumulation and strengthening in $\mathrm{Cu}$ thin films. Acta Mater 49:2365-2372.

Wiederhirn G. 2007. The strength limits of ultra-thin copper films. PhD Thesis, Max Plack Institut für Metallforschung, Stuttgart, Germany. 